\title{
Towards sustainable communities: Socioeconomic determinants of domestic water consumption in Surakarta City, Indonesia
}

\author{
Paramita Rahayu ${ }^{1, *}$ and Erma Fitria Rini $^{1}$ \\ ${ }^{1}$ Universitas Sebelas Maret, Jl. Ir. Sutami 36 A Surakarta
}

\begin{abstract}
The gap in water consumption among urban households remains obvious in most cities in Indonesia. It is particularly the case for high-density urban areas. Dense urban areas and limited availability of water resource position water as a contested resource. Regarding water as a contested resource, this paper aims to identify the socioeconomic determinants influencing levels of water consumption in the urbanized medium-sized city, using the case of Surakarta City. Data were collected by using proportional random sampling. Valid respondents are 356 households out of 400 respondents. Respondents were proportioned according to served and not served by networked water PDAM. The data are analyzed by using multiple regression. The result shows that, with 95 percent significance level, overall, age of head of household, total monthly income, housing type, the number of water source utilized by every household, total number of people in every household, and total person work in every household have simultaneously become factors determining water consumption of households in Surakarta. The socioeconomic variables are able to explain 16 percent of the whole factors determining household water consumption in Surakarta City. Even though many factors remain unexplained, this study reveals several important factors that often cause the marginalization of certain urban communities from appropriate domestic water in a rapidly growing secondary city.
\end{abstract}

\section{Introduction}

Water influence not only physical and social activities of the community but also a community's economic development [1]. Unfortunately, the gap of water consumption in urban areas is obvious. Socioeconomic characteristics of the community are regarded as variables that influencing the level of water consumption of every household [2]. Previous studies that discuss problematic water supply have focused on large cities and big metropolis [3]. Therefore, more research on the water problem in small to medium-sized cities is important. Having said this, this paper will focus on a medium-sized city in Java. Just like a density of big metropolis, Surakarta City has a density of 13,181 people $/ \mathrm{km}^{2}$ [4]. Within such high density, urban clean water will be risky to be highly contested. This

\footnotetext{
*Corresponding author: paramitarahayu@staff.uns.ac.id
} 
situation will be particular for the community under the category of lower income urban population. Given this risk, the under-research of medium-sized cities on water problem, and the influence of socioeconomic factors to the daily level of urban clean water consumption, this study will investigate socioeconomic factors that determine domestic water consumption in Surakarta City, as an example of a rapidly urbanized medium-sized city in Java.

\section{Literature Review}

It is argued that one among many understandings of sustainable development is about the relationships of development, what people perceived on development, and natural resources [3]. Debate on sustainable development then grows into a debate of "sustainability" of the Northern countries and "sustainable development" of the Southern countries [4]. Sustainability focuses on maintaining the standard of living, while the sustainable development's main argument is about ensuring that people will survive with enough available resources. The first is well-known as green sustainable development, while the latter is a brown sustainable development [5,6,7]. Many arguments about brown sustainable development discuss equity of distribution of basic public services such as water and sanitation, electricity, education, healthcare, and the problem of disparity of their distribution [8]. Increasing access to basic services is commonly called the social dimension of sustainable development [8]. Other scholars argue that brown sustainable development is particularly focused on the local provision of basic services [9]. As basic services are contested among the population, mostly in rapidly growing urban areas, discussion on brown sustainable development revolves around local-equity of basic service distribution. It is debating on difference access of poor and non-poor of the urban population, or among those of the poor urban population $[10,11,12]$.

Water is one of the most important basic service yet problematic in terms of its distribution and availability; therefore, this resource should be managed appropriately with regard to achieving sustainable development $[13,14,15]$. Well-managed water resources in a rapidly urbanized area are important because rapid urbanization will affect water security [16]. Under contested and problematic distribution and availability of water in urban areas, lower income population commonly takes the most negative impact. The situation will be getting worse for the poor urban population as efforts of the poor urban population to adapt to a marginal condition is commonly a trade-off to other aspects of welfare, which possibly reinforcing their poverty [17].

Furthermore, those who live in a slum and illegal site commonly do not have the right to formal urban service delivery, including water, from the government [1]. A similar situation applied for those who live at the urban fringe of the city due to a limited network of piped water supply [18]. The disadvantage of the geographic factor will be reinforced by the unavailability of reliable water resource or an adequate alternative of the water resource to urban population. In addition to this geographical location, the study in 286 Chinese cities reveals several factors that influence water consumption per capita per day, those are meteorological factors, socioeconomic status, water supply, and conservation factors [2]. From this study, it is proved that socioeconomic characteristics of urban households determining their level of water consumption. Therefore, related to the disadvantaged group of the urban population, the overall access and strategy to water and sanitation should be defined by geographic, demographic, and socioeconomic factors [19]. Understanding these factors will make possible to target the most effective intervention [20,21].

It can be concluded that rapid urbanization affects water security. The level of consumption of water per day among the urban population is risky to a significant difference. It is not only among poor and non-poor one but also in a slum area itself, there 
exist significant diversity and differences of access to drinking water [11]. In addition, the level of water consumption among urban inhabitants will be risky to be insufficient to a certain standard of water consumption. Among the many factors that affect the level of water consumption, one important factor is the socioeconomic factor. Understanding this factor will be important in considering to whom access to water should be improved.

\section{Method and Description of Study Area}

Multiple regression analysis is an analysis used to determine the effect of 2 or more independent variables on other variables. In multiple regression analysis, basic decision making is based on two types of statistical tests, t-Test t, and F-Test. The t-test aims to determine whether there is a partial or independent influence from one independent variable to a dependent variable. For example is there any effect of income on the quantity of water needed or is there the influence of the head of the household on the quantity of water required. While F-test aims to determine whether or not there is a simultaneous influence or additional influence of all independent variables on the dependent variable. This study will investigate 6 variables and their influence on the quantity of water used on a daily basis by urban households.

Regarding hypothesis formulation, this study formulates seven hypotheses. Six hypotheses relate to six socioeconomic variables that are being tested regarding their influence to the quantity of water used by urban households, and one hypothesis relates to the influence of the whole set of variables to the quantity of water used by the urban household. The significance level of this regression model is 95 percent. The seven hypotheses are as follow:

$\mathrm{H} 1=$ There is an effect of age (X1) on the quantity of water used (Y)

$\mathrm{H} 2=$ There is an effect of the total number of people living in the house (X2) on the quantity of water used (Y)

$\mathrm{H} 3=$ There is an effect of total income (X3) on the quantity of water used (Y)

$\mathrm{H} 4=$ There is an effect of the number of people working (X4) on the quantity of water used (Y)

$\mathrm{H} 5=$ There is an effect of house type (X5) on the quantity of water used (Y)

H6 $=$ There is an effect of the number of water source used (X6) on the quantity of water used (Y)

$\mathrm{H} 7$ = There is an effect of age (X1), total number of people living in the house (X2), total income (X3), number of people working (X4), housing type (X5), and the number of water source used (X6) simultaneously to the quantity of water used (Y)

To contextualize the multiple regression model in this study, the description of Surakarta City will be discussed. Surakarta is a medium-sized city located in the southeastern part of Central Java Province. The city is the second largest city in the Province. It has 580 thousand inhabitants, and $44 \mathrm{~km}^{2}$ area wide. Its density is nearly 14000 persons $/ \mathrm{km}^{2}$. Surakarta City consists of five sub-districts (kecamatan) and fifty-one urban villages (kelurahan). The densest kecamatan reach density of 20 thousand people $/ \mathrm{km}^{2}$. The city is rapidly growing in terms of its urban activities. The main sector contributes to its GRDP is secondary sectors (processed and construction industry), and tertiary sector (commerce and trade). The development of the sector's contribution during the last 30 years indicates the higher needs of water for urban activities over the years. The level of absolute poverty is about 10 percent of all population. Such poverty is defined if every person in every household could not afford the level of consumption of IDR. 448.062/person/month, based on the standard of Central Bureau of Statistics [22]. For networked water in 
Surakarta City, similar to all other cities in Indonesia, the service is provided by local government enterprise for water supply called PDAM (Perusahaan Daerah Air Minum). PDAM Surakarta City is currently able to provide merely about half of the city's household with its service.

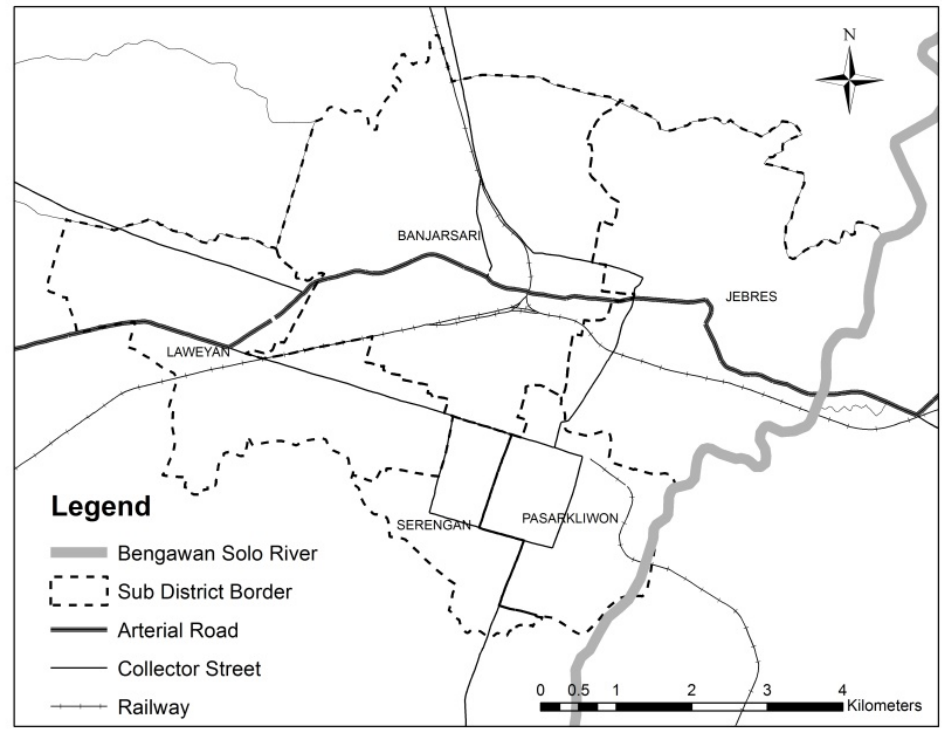

Fig. 1. Surakarta City

\section{Result}

The general pattern of water consumption of 356 respondents sharply divides the level of water consumption between those who are connected to networked water PDAM and those who are not connected to networked water PDAM. The data show that respondents connected to networked water PDAM are able to consume significantly more amount of water for their domestic activities compared to those who are not. The general pattern of monthly income shows the similar tendency. Urban household connected to networked water PDAM sows higher average monthly income compared to those who are not connected to networked water PDAM.

Table 1. Coefficients ${ }^{\text {a }}$

\begin{tabular}{|l|r|r|r|r|r|}
\hline \multirow{2}{*}{ Model } & \multicolumn{2}{|c|}{ Unstd Coeff } & Std Coeff & \multirow{2}{*}{$\mathrm{t}$} & \multirow{2}{*}{ Sig. } \\
\cline { 2 - 4 } & \multicolumn{1}{|c|}{ B } & Std. Error & Beta & & \\
\hline (Constant) & 55.874 & 38.063 & & 1.468 & .143 \\
Age (X1 ) & 1.130 & .567 & .100 & 1.994 & .047 \\
Total family number ( X2 ) & -6.597 & 4.558 & -.083 & -1.447 & .149 \\
Family Income ( X3 ) & $6.170 \mathrm{E}-6$ & .000 & .229 & 4.095 & .000 \\
Number of the worker in the & 2.160 & 8.004 & .016 & .270 & .787 \\
family ( X4 ) & .256 & .074 & .192 & 3.465 & .001 \\
House type ( X5 ) & 22.394 & 10.139 & .110 & 2.209 & .028 \\
Number of domestic water & & & & & \\
source (X6 ) & & & & & \\
\hline
\end{tabular}

a. Dependent Variable: Water quantity (Y) 


\section{First Hypothesis Testing (H1)}

Sig value is known. for the effect of $\mathrm{X} 1$ to $\mathrm{Y}$ is equal to $0,047<0,05$ and $\mathrm{t}$ value count $1,994>1,968$. So it can be concluded that $\mathrm{H} 1$ is accepted which means there is an influence of age of the head of household (X1) to the quantity of water used per person per day (Y).

\section{Testing The second hypothesis (H2)}

Sig value is known. for the effect of $\mathrm{X} 2$ to $\mathrm{Y}$ is equal to $0,149>0,05$ and $\mathrm{t}$ value count $1,447<1,968$. So it can be concluded that $\mathrm{H} 2$ is rejected which means there is no influence between the total family number (X2) to the quantity of water used per person (Y).

\section{Testing The third hypothesis $(\mathrm{H} 3)$}

Sig value is known. for the effect of $\mathrm{X} 3$ on $\mathrm{Y}$ is $0.000<0,05$ and $\mathrm{t}$ count value 4,095>t table 1,968. So it can be concluded that $\mathrm{H} 3$ is accepted which means there is an influence between income (X3) on the quantity of water used per person (Y).

\section{Testing The fourth hypothesis (H4)}

Sig value is known. for the effect of $\mathrm{X} 4$ to $\mathrm{Y}$ is $0,787>0,05$ and t value count $0,270<\mathrm{t}$ table 1,968 . So it can be concluded that $\mathrm{H} 4$ is rejected which means there is no influence between the number of the worker in the family (X4) with the quantity of water used per person (Y).

\section{Testing The fifth hypothesis (H5)}

Sig value is known. for the effect of $\mathrm{X} 5$ to $\mathrm{Y}$ is $0.001<0.05$ and the value of $\mathrm{t}$ arithmetic $3.465>\mathrm{t}$ table 1.968. So that H5 is accepted which means there is influence between house type (X5) to the quantity of water used (Y).

\section{Testing The sixth hypothesis (H6)}

Sig value is known. for the effect of $\mathrm{X} 6$ to $\mathrm{Y}$ is $0,028<0,05$ and $\mathrm{t}$ value $2,209>\mathrm{t}$ table 1,968 . So $\mathrm{H} 6$ is accepted which means there is influence between the number of domestic water source (X6) to the quantity of water used per person (Y).

Table 2. ANOVA ${ }^{\mathrm{a}}$

\begin{tabular}{|l|r|r|r|r|r|}
\hline \multicolumn{1}{|c|}{ Model } & Sum of Squares & \multicolumn{1}{c|}{ df } & Mean Square & F & Sig. \\
\hline Regression & 719987.724 & 6 & 119997.954 & 11.098 & $.000^{\mathrm{b}}$ \\
Residual & 3784385.029 & 350 & 10812.529 & & \\
Total & 4504372.753 & 356 & & & \\
\hline
\end{tabular}

a. Dependent Variable: Water quantity (Y)

b. Predictors: (Constant), Number of domestic water source (X6), Age (X1), Total family number (X2), Family Income (X3), House type (X5), Number of the worker in a family (X4)

\section{Testing of the Seventh Hypothesis (H7}

Based on the above output, it is known that the significance value of $\mathrm{X} 1, \mathrm{X} 2, \mathrm{X} 3, \mathrm{X} 4, \mathrm{X} 5$, and $\mathrm{X} 6$ effect simultaneously on $\mathrm{Y}$ is $0.000<0,05$ and $\mathrm{F}$ value is $11.098>\mathrm{F}$ table 2.12. So it 
can be concluded that $\mathrm{H} 7$ is accepted which means there is influence $\mathrm{X} 1, \mathrm{X} 2, \mathrm{X} 3, \mathrm{X} 4, \mathrm{X} 5$, and X6 simultaneously to $\mathrm{Y}$.

Table 3. Model Summary

\begin{tabular}{|l|r|r|r|c|}
\hline Model & R & R Square & $\begin{array}{c}\text { Adjusted R } \\
\text { Square }\end{array}$ & $\begin{array}{c}\text { Std. Error of the } \\
\text { Estimate }\end{array}$ \\
\hline 1 & $.400^{\mathrm{a}}$ & .160 & .145 & 103.98331 \\
\hline
\end{tabular}

a. Predictors: (Constant), Number of domestic water source (X6), Age ( X1), Total family number ( X2 ), Family Income ( X3 ), House type ( X5), Number of the worker in a family ( X4)

Based on the above output it is known that the $\mathrm{R}$ square value is 0.160 , this means that the influence of variables $\mathrm{X} 1, \mathrm{X} 2, \mathrm{X} 3, \mathrm{X} 4, \mathrm{X} 5$, and $\mathrm{X} 6$ on the $\mathrm{Y}$ variable, simultaneously, is $16 \%$.

\section{Discussion and Conclusion}

The minimum standard of daily water consumption from World Health Organization is 50 liters/person/day, while the minimum standard for the urban population living in the medium-sized city according to the Indonesian Ministry of Public Works is 120 liters/person/day. From the statistical descriptive and the multiple regression's results in the previous sections, this study is able to discuss several important points to be aware of for key stakeholders in the water supply system.

First, for Surakarta City, in average, respondents connected to networked water PDAM consume water for domestic need 175 liters/person/day, while those who are not connected consume 61,9 liter/person/day for their domestic need. We can see the significant different level of water consumption between the two groups. Even though both groups remain able to fulfill the daily minimum standard of water consumption of WHO for domestic needs, this sharp difference should be a point of awareness for key stakeholders of water supply system of Surakarta City. This finding indicates that being able to be connected to the networked water is an essential factor to raise urban households' capacity to fulfill their domestic water consumption in accordance to the minimum standard of Indonesian medium-sized city.

Second, water consumption is highly influenced by the capacity to pay for water. The literature review discussed above mentioned that there is a propensity of the marginalization of certain communities with regard to accessing appropriate level of water consumption. Therefore, the data of statistical description and multiple regression show that poor urban household will be risking at consuming less water as their propensity to pay for water is lower.

Third, water consumption is influenced by housing type. Housing type relates to the location of the house in the city. The smaller house will tend to locate in a local and narrow street or tend to locate in a dense neighborhood, while the bigger house type tends to locate along the main street or wider street, and in a less dense neighborhood. The problem of old and dense urban settlement is that they will have difficulties to be penetrated by networked services, particularly water. Not only does technical reason in constructing water pipes appear, but also the unwillingness or low capacity of the community of such neighborhood to pay for the initial deposit for constructing water piped networks in their neighborhood exist. Similar to but different character from what have been discussed, in which geographical location determines access of urban population to services related to slum and 
non-slum settlement, from the spatial perspective[1], this study shows that it is important for the city's key stakeholders to pay close attention to not only slum area, but also dense urban neighborhood, by providing them with on-site water source alternative. This on-site water alternative will be a reliable and affordable water source for such neighborhood.

Fourth, water consumption is influenced by the age of the head of the household. This factor is actually closely related to the economic status of the urban households. Age of urban household within a range of productive age will have more propensity to have a stable income.

The last important point to reveal is that relation between the number of water source used by urban households with the level of daily water consumption per capita per day. For Indonesian context, there two main types of domestic water source: traditional household well and networked water PDAM. However, the data shows that even though the two types of water source remain the main source contribute to the daily water consumption, it is more than half of respondents combine their domestic water source with bottled water, water vendor, communal tap water, as well as, for those connected to networked water PDAM, some of them remain using household well. A variation of a number of domestic water source indicates that the main source of domestic water of urban household is not reliable enough to satisfy different types of domestic needs such as drinking, cooking, bathing, washing and so on. Therefore, increasing the reliability of the main source of domestic water is necessary.

To conclude, this study suggests that more research should be done to explore in more detail factors that explain the water consumption of the urban household, both in socioeconomic aspects or in other aspects. Further study relates to this determinant will be important to understand what strategy should be implemented to create a better distribution of domestic water for the urban household.

\section{References}

1. E.W. Dungumaro. Socioeconomic differentials and availability of domestic water in South Africa. Physics and Chemistry of the Earth 32, 1141-1147 (2007)

2. L. Fan, L. Gai, Y. Tong, R. Li. Urban water consumption and its influencing factors in China: Evidence from 286 cities. Journal of Cleaner Production 166, 124-133 (2017).

3. Sharma, A. Sustainable and Socially Inclusive Development of Urban Water Provisioning: A Case of Patna. Environment and Urbanization Asia 6,(1), 28-40 (2015).

4. Indonesia National Census. 2010. Badan Pusat Statistik.

5. M. Redclift. Sustainable Development: Exploring the Contradictions. Routledge: London and New York (1987).

6. D. Mitlin. Sustainable Development: A guide to the literature. Environment and Urbanization 4, (1), 111-24 (1992).

7. A. Allen, and N. You. Sustainable Urbanization: Bridging the Green and Brown Agendas. Development Planning Unit, University College London. London (2002).

8. K. Gazzeh, I.S Abubakar. Regional disparity in access to basic public services in Saudi Arabia: A sustainability challenge. Utilities Policy 52, 70-80 (2018).

9. G. McGranahan and D. Satterthwaite. Environmental health or ecological sustainability? Reconciling the brown and green agendas in urban development in Planning in Cities. Ed. R. Zetter and R. White, 43-57. Practical Action Publishing: Wales (2015). 
10. K. Schwartz, J. Gupta, M. Tutusaus. Editorial - Inclusive development and urban water services, Habitat International, 73, 96-100(2018)

11. N. Uddin. Assessing urban sustainability of slum settlements in Bangladesh: Evidence from Chittagong city. Journal of Urban Management, 7, 32-42 (2018)

12. S. Narayanan, A.T Rajan, P. Jebaraj, M.S. Elayaraja. Delivering basic infrastructure services to the urban poor: A meta-analysis of the effectiveness of bottom-up approaches, Utilities Policy, xxx, 1-13 (2017)

13. F. Pellicer-Martínez and J. M. Martínez-Paz. The Water Footprint as an indicator of environmental sustainability in water use at the river basin level. Science of The Total Environment, 571, 561-574 (2016).

14. M. Karatayev, Z. Kapsalyamovab, L. Spankulovac, A. Skakova, G. Movkebayevae, A. Kongyrbayd. Priorities and challenges for a sustainable management of water resources in Kazakhstan, Sustainability of Water Quality and Ecology 9-10, 115-135 (2017).

15.Z. Jiaa, Y. Caia, Y. Chenb, W. Zenga. Regionalization of water environmental carrying capacity for supporting the sustainable water resources management and development in China. Resources, Conservation \& Recycling 134, 282-293 (2018) .

16. J. Cai, H. Yin, O. Varis, Impacts of urbanization on water use and energy-related CO2 emissions of residential consumption in China: A spatiotemporal analysis during 20032012, Journal of Cleaner Production doi: 10.1016/j.jclepro.2018.05.117 (2018).

17. H. Eakina, et al. Adapting to risk and perpetuating poverty: Household's strategies for managing flood risk and water scarcity in Mexico City, Environmental Science \& Policy 66, 324-333 (2016).

18. M. Ranganathana and C. Balazs, Water marginalization at the urban fringe: Environmental justice and urban political ecology across the North-South divide. Urban Geography, 36(3), 403-423 (2015).

19. T.T. Tuyet-Hanh, et al., Household trends in access to improved water sources and sanitation facilities in Vietnam and associated factors: Findings from the Multiple Indicator Cluster Surveys, 2000-2011, Global Health Action, 9:1, 29434, DOI: 10.3402/gha.v9.29434

20. A.V. Kulinkina, et al. Piped water consumption in Ghana: A case study of temporal and spatial patterns of clean water demand relative to alternative water sources in rural small towns, Science of the Total Environment, 559, 291-301 (2016).

21. M. Jain, Y. Lim, J.A Arce-Nazario, M. Uriarte. Perceptional and socio-demographic factors associated with household drinking water management strategies in rural Puerto Rico. PLoS ONE 9, 2, 88059. doi:10.1371/journal.pone.0088059 (2014)

22. BPS (Central Bureau of Statistics) (2018). Monthly Report of Social Economic Data. Jakarta 